\title{
The immunohistochemical expression of SSTR2A is an independent prognostic factor in meningioma
}

\author{
Christina Fodi ${ }^{1,2} \cdot$ Marco Skardelly $^{1,2}$. Johann-Martin Hempel ${ }^{2,3}$. Elgin Hoffmann ${ }^{2,4}$. Salvador Castaneda ${ }^{2,5}$. \\ Ghazaleh Tabatabai $^{1,2,6,7,8} \cdot$ Jürgen Honegger ${ }^{1,2} \cdot$ Marcos Tatagiba $^{1,2} \cdot$ Jens Schittenhelm ${ }^{2,9} \cdot$ Felix Behling $^{1,2,7}$ (i)
}

Received: 7 June 2021 / Revised: 8 September 2021 / Accepted: 19 September 2021 / Published online: 2 October 2021

(c) The Author(s) 2021, corrected publication 2022

\begin{abstract}
The expression of somatostatin receptors in meningioma is well established. First, suggestions of a prognostic impact of SSTRs in meningioma have been made. However, the knowledge is based on few investigations in small cohorts. We recently analyzed the expression of all five known SSTRs in a large cohort of over 700 meningiomas and demonstrated significant correlations with WHO tumor grade and other clinical characteristics. We therefore expanded our dataset and additionally collected information about radiographic tumor recurrence and progression as well as clinically relevant factors (gender, age, extent of resection, WHO grade, tumor location, adjuvant radiotherapy, neurofibromatosis type 2, primary/recurrent tumor) for a comprehensive prognostic multivariate analysis $(n=666)$. The immunohistochemical expression scores of SSTR1, 2A, 3,4 , and 5 were scored using an intensity distribution score ranging from 0 to 12 . For recurrence-free progression analysis, a cutoff at an intensity distribution score of 6 was used. Univariate analysis demonstrated a higher rate of tumor recurrence for increased expression scores for SSTR2A, SSTR3, and SSTR4 ( $p=0.0312, p=0.0351$, and $p=0.0390$, respectively), while high expression levels of SSTR1 showed less frequent tumor recurrences $(p=0.0012)$. In the Kaplan-Meier analysis, a higher intensity distribution score showed a favorable prognosis for SSTR1 $(p=0.0158)$ and an unfavorable prognosis for SSTR2A (0.0143). The negative prognostic impact of higher SSTR2A expression remained a significant factor in the multivariate analysis (RR 1.69, $p=0.0060$ ). We conclude that the expression of SSTR2A has an independent prognostic value regarding meningioma recurrence.
\end{abstract}

Keywords Meningioma $\cdot$ Prognosis $\cdot$ Recurrence-free survival $\cdot$ Somatostatin receptor $\cdot$ SSTR $\cdot$ Immunohistochemistry . Tissue microarray

Felix Behling

felixbehling@yahoo.de

1 Department of Neurosurgery, University Hospital Tübingen, Eberhard-Karls-University Tübingen, Hoppe-Seyler Street 3, Tübingen, Germany

2 Center for CNS Tumors, Comprehensive Cancer Center Tübingen-Stuttgart, University Hospital Tübingen, Eberhard-Karls-University Tübingen, Tübingen, Germany

3 Department of Diagnostic and Interventional Neuroradiology, University Hospital Tübingen, Eberhard-Karls-University Tübingen, Tübingen, Germany

4 Department of Radiation-Oncology, University Hospital Tübingen, Eberhard-Karls-University Tübingen, Tübingen, Germany
5 Department of Nuclear Medicine, University Hospital Tübingen, Eberhard-Karls-University Tübingen, Tübingen, Germany

6 Department of Neurology \& Interdisciplinary Neuro-Oncology, University Hospital Tübingen, Eberhard-Karls-University Tübingen, Tübingen, Germany

7 Hertie Institute for Clinical Brain Research, Tübingen, Germany

8 German Cancer Consortium (DKTK), DKFZ Partner Site Tübingen, Tübingen, Germany

9 Department of Neuropathology, University Hospital Tübingen, Eberhard-Karls-University Tübingen, Tübingen, Germany 


\section{Introduction}

Meningiomas represent the most common benign intracranial tumor [1]. Most cases can be treated effectively by surgical resection, but treatment of recurrent tumors can be challenging. Besides surgery and radiotherapy, no established treatment options for meningiomas exist [2]. Recently, the role of early surgical intervention for recurrent meningioma has been suggested [3]. Therefore, it is important to improve the identification of patients with an increased risk of recurrence. This has also been expressed by the update of the WHO classification of central nervous system tumors in 2016. Since then, invasion of central nervous system tissue by meningioma cells has been established as a standalone criterion for atypia [4]. A DNA methylation-based classification has been proclaimed as superior to the WHO classification for deciding for adjuvant radiation [5]. Molecular findings associated with increased tumor recurrence risk such as TERT promotor mutation and CDKN2A/B deletion are seen only in a small subset of the tumors [6]. Besides these recently described aspects, the detection of patients with an increased risk of recurrence is still insufficient.

One feature of meningiomas that has been utilized for a novel targeted treatment approach is the expression of somatostatin receptors (SSTR2) [7, 8]. Peptide receptor radionuclide therapy seems to be an effective measure for challenging and recurrent meningiomas $[9,10]$. Furthermore, a few studies with small meningioma cohorts have focused on the effect of the expression of SSTRs on proliferation and prognosis with mixed results [11-13]. So far, the prognostic potential of SSTR expression in meningiomas has not been further clarified. We have recently described the expression of SSTR1-5 in a large cohort of over 700 meningiomas and characterized expression differences in clinical subgroups such as WHO grade and neurofibromatosis 2 [14]. Due to the importance of more accurate prognostic evaluation of meningiomas, we expanded our initial dataset and collected information about radiographic tumor recurrence and progression as well as other established prognostic factors. The goal of this retrospective study is to evaluate the prognostic role of somatostatin receptor expressions in meningiomas and its impact on tumor recurrence in a large retrospective cohort with a comprehensive prognostic multivariate analysis.

\section{Materials and methods}

\section{Patient cohort}

Data on the immunohistochemical expression of SSTR1-5 in a cohort of 724 meningiomas together with clinical characteristics (gender, age, primary/recurrent tumor, prior radiotherapy, neurofibromatosis type 2 , localization, and WHO classification) was collected from our previous study [14]. For the prognostic evaluation, we additionally gathered information about radiographic tumor recurrence/progression as well as applied adjuvant radiotherapy between surgery and tumor recurrence/progression and the extent of resection according to Simpson grade. Tumor recurrence was defined if a clear tumor recurrence was seen and tumor progression if residual tumor showed clear progression on follow-up imaging. All radiographic reports and images were critically reviewed for this study. Complete follow-up data was available for 666 cases. Sufficient staining results were attained for 650, 654, 654, 655, and 657 cases for SSTR1, SSTR2A, SSTR3, SSTR4, and SSTR5, respectively.

\section{Tissue microarray and immunohistochemistry}

Existing tissue microarray (TMA) data of 666 meningiomas that were stained for SSTR 1 (Gramsch, Schwabhausen, Germany), SSTR2 (Dianova, Hamburg, Germany analysis), SSTR3 (Abcam, Cambridge, United Kingdom), SSTR4 (Gentex, Zeeland, USA), and SSTR5 (Abcam, Cambridge, UK) were examined. Two sample cylinders of $1 \mathrm{~mm}$ diameter were extracted for each tumor for TMA construction. For TMA construction and immunohistochemistry protocol, details are shown in Behling et al. [14].

\section{Microscopic assessment and statistical methods}

An intensity distribution score described by Barresi et al. for immunohistochemical evaluation of somatostatin receptors was used to summarize expression data [12]. The immunostaining intensity was scored as negative (0), weak (1), intermediate (2), or strong (3). The area of positivity was estimated as follows: $0(0-5 \%), 1(5-25 \%), 2(25-50 \%)$, $3(50-75 \%)$, and $4(75-100 \%)$. The intensity score was multiplied by the area of positivity, leading to an intensity distribution score of $0-12$. The cutoff for dichotomizing the cohort was chosen at a score $>/=6$. The Pearson's chisquared and log-rank tests were used for univariate and the cox proportional hazard model for multivariate analysis. A significance level of $\alpha<0.05$ was applied. A classification 
and regression tree (CART) analysis was used to define prognostic cutoff for age.

\section{Results}

\section{Clinical characteristics and SSTR expression of the study cohort}

The basic clinical characteristics and the immunohistochemical expression scores of the somatostatin receptors 1, 2A, 3,4 , and 5 of our study cohort have been described in detail in our previous work [14]. We have provided a supplementary table with the distribution and clinical characteristics of this cohort which displays only 666 cases of the original 726 tumors since follow-up data was only available for 91.7\% (Supplementary Table 1). The mean follow-up was 27.7 months ranging from 1.1 to 195.6 months. Complete resection was achieved in 70.9\% (Simpson grade I, II, and III), and a subtotal resection was done in $29.1 \%$ (Simpson grade IV or V). The decision for adjuvant radiation therapy was made in 33 cases (5\%). Details are displayed in Table 1. We collected information about radiographic tumor recurrence and progression as well as other established prognostic factors. Tumor recurrence or progression of residual tumor was observed in 137 of 666 cases (20.6\%).

\section{Univariate analysis}

The results of the univariate analysis using the intensity distribution score cutoff at $>/=6$ are displayed in Table 1 . For SSTR1, 415 cases $(63.8 \%)$ reached a score of 6 or higher, while $236(36.3 \%)$ scored below the cutoff. Tumors with a lower expression score had a higher recurrence rate $(27.5 \%$ vs. $16.9 \%, p=0.0012)$. An intensity distribution score of 6 or higher for SSTR2A was observed in 293 tumor (44.7\%) and below in $362(55.3 \%)$ cases. Higher expression was associated with an increased recurrence rate $(24.2 \%$ compared to $17.4 \%, p=0.0312$ ). The expression scores for SSTR3 and SSTR4 were quite low. For SSTR3, only 42 cases reached an intensity distribution score of 6 or higher $(6.4 \%)$, and with $93.6 \%(n=613)$, the majority of tumors scored below the cutoff. An even lower number of higher expression scores $(>/=6)$ was observed with 24 cases $(3.7 \%)$. For both, SSTR3 and SSTR4, the few cases with higher expressions had a higher rate of tumor recurrences with $33.2 \%$ $(p=0.0351)$ and $37.5 \%(p=0.0390)$, respectively. An intensity distribution score above the cutoff of 6 was observed in 189 cases for SSTR5 (28.7\%). There was no significant difference in the rate of tumor recurrence compared to the 469 tumors with a lower expression score.

In the Kaplan-Meier analysis, higher expression of SSTR1 and lower expression scores of SSTR2A showed a more favorable progression-free survival (Fig. 1). The univariate results of all other included prognostic factors are shown in Table 1 and Fig. 2.

\section{Multivariate analysis}

All clinical factors were included in the multivariate analysis together with the intensity distribution scores for SSTR15. Male gender, younger age, recurrent tumor, incomplete resection, and higher WHO grade were risk factors for tumor recurrence ( $p=0.0042, p=0.0380, p<0.0001, p=0.0005$, and $p<0.0001$, respectively). Adjuvant radiotherapy was an independent positive prognostic factor $(p=0.0004)$. Neurofibromatosis type 2 and tumor location lost its prognostic significance when the other predictors of recurrence were included in a multivariate analysis (compared to the univariate analysis, see Table 1).

Higher intensity distribution scores for SSTR2A remained an independent negative prognostic factor $(p=0.0060)$, while SSTR1, SSTR3, SSTR4, and SSTR5 had no influence on progression-free survival. The details of the multivariate analysis are displayed in Table 2, and corresponding graphs are shown in Fig. 1.

\section{Discussion}

The improvement of the prognostic assessment of meningiomas beyond the current WHO classification has been investigated for many years and led to the update of the WHO classification for meningiomas in 2016 with CNS invasion being now regarded as a stand-alone criterion for atypia [4]. Additionally, a DNA methylation-based classification and TERT promoter mutation status analysis are among the most promising advances with the potential to further refine the prognostic evaluation of meningiomas $[5,15]$ but currently do not provide a target for treatment.

The expression of somatostatin receptors in meningiomas has been utilized for the implementation of peptide radio receptor therapy in selected cases with reports of good efficacy $[9,10]$. We have recently described the distribution of the somatostatin receptors 1,2A, 3, 4, and 5 in a large meningioma cohort using immunohistochemical staining and a semiquantitative assessment score to help form the basis for the development of a differentiated and improved peptide radioreceptor therapy [14]. We observed differences in the SSTR expression in certain clinical and histopathological subgroups. Among these subgroups, a lower expression of SSTR1 was seen in recurrent tumors compared to primary meningiomas, while no differences regarding other SSTRs were observed. Now we present the first multivariate evaluation of all somatostatin receptors and its prognostic impact on meningioma recurrence in a comprehensive cohort of 
Table 1 Univariate analysis of prognostic factors in meningioma (Pearson's chisquared test)

\begin{tabular}{|c|c|c|c|c|}
\hline & \multirow[b]{2}{*}{$N(\%)$} & \multicolumn{2}{|c|}{ Tumor recurrence } & \multirow[b]{2}{*}{$p$-value $($ Prob $>$ Chisq $)$} \\
\hline & & Yes & No & \\
\hline \multicolumn{5}{|l|}{ Gender } \\
\hline Female & $462(69.4)$ & $67(14.5)$ & $395(85.5)$ & \multirow[t]{2}{*}{$<0.0001^{*}$} \\
\hline Male & $204(30.6)$ & $70(34.3)$ & $134(65.7)$ & \\
\hline \multicolumn{5}{|l|}{ Age } \\
\hline$<39.48$ & $91(13.7)$ & $35(38.5)$ & $56(61.5)$ & \multirow[t]{2}{*}{$<0.0001^{*}$} \\
\hline$>=39.48$ & $575(86.3)$ & $102(17.7)$ & $473(82.3)$ & \\
\hline \multicolumn{5}{|c|}{ Recurrent meningioma } \\
\hline Primary & $562(84.4)$ & $491(87.4)$ & $71(12.6)$ & \multirow[t]{2}{*}{$<0.0001^{*}$} \\
\hline Recurrence & $104(15.6)$ & $38(36.5)$ & $66(63.5)$ & \\
\hline \multicolumn{5}{|c|}{ Adjuvant radiotherapy } \\
\hline Yes & $33(5.0)$ & $8(24.2)$ & $25(75.8)$ & \multirow[t]{2}{*}{0.5925} \\
\hline No & $633(95.1)$ & $129(20.4)$ & $504(79.6)$ & \\
\hline \multicolumn{5}{|l|}{ Simpson grade } \\
\hline$<4$ & $466(70.9)$ & $64(13.7)$ & $402(86.3)$ & \multirow[t]{2}{*}{$<0.0001^{*}$} \\
\hline$>=4$ & $191(29.1)$ & $72(37.7)$ & $119(62.3)$ & \\
\hline \multicolumn{5}{|c|}{ WHO classification 2016} \\
\hline I & $538(80.8)$ & $64(11.9)$ & $474(88.1)$ & \multirow[t]{3}{*}{$<0.0001 *$} \\
\hline II & $106(15.9)$ & $54(50.9)$ & $52(49.1)$ & \\
\hline III & $22(3.3)$ & $19(86.4)$ & $3(13.6)$ & \\
\hline \multicolumn{5}{|l|}{ NF2 } \\
\hline Yes & $62(9.3)$ & $27(43.6)$ & $35(56.5)$ & \multirow[t]{2}{*}{$<0.0001 *$} \\
\hline No & $604(90.7)$ & $110(18.2)$ & $494(81.8)$ & \\
\hline \multicolumn{5}{|l|}{ Location } \\
\hline Convexity/falx & $265(39.8)$ & $63(23.8)$ & $202(76.2)$ & \multirow{3}{*}{$0.0111^{*}$} \\
\hline Skull base & $340(51.1)$ & $70(20.6)$ & $270(79.4)$ & \\
\hline Spinal & $61(9.2)$ & $4(6.6)$ & $57(93.4)$ & \\
\hline \multicolumn{5}{|l|}{ SSTR1 $(n=651)$} \\
\hline$>/=6.0$ & $415(63.8)$ & $70(16.9)$ & $345(83.1)$ & \multirow[t]{2}{*}{$0.0012 *$} \\
\hline$<6.0$ & $236(36.3)$ & $65(27.5)$ & $171(72.5)$ & \\
\hline \multicolumn{5}{|l|}{ SSTR2A $(n=655)$} \\
\hline$>/=6.0$ & $293(44.7)$ & $71(24.2)$ & $222(75.8)$ & \multirow[t]{2}{*}{$0.0312 *$} \\
\hline$<6.0$ & $362(55.3)$ & $63(17.4)$ & $299(82.6)$ & \\
\hline \multicolumn{5}{|l|}{ SSTR3 $(n=655)$} \\
\hline$>/=6.0$ & $42(6.4)$ & $14(33.2)$ & $28(66.7)$ & \multirow[t]{2}{*}{$0.0351^{*}$} \\
\hline$<6.0$ & $613(93.6)$ & $121(19.7)$ & $492(80.3)$ & \\
\hline SSTR4 $(n=656)$ & & & & \\
\hline$>/=6.0$ & $24(3.7)$ & $9(37.5)$ & $15(62.5)$ & $0.0390 *$ \\
\hline$<6.0$ & $632(96.3)$ & $127(20.1)$ & $505(79.9)$ & \\
\hline SSTR5 $(n=658)$ & & & & \\
\hline$>/=6.0$ & $189(28.7)$ & $41(21.7)$ & $148(78.3)$ & 0.6804 \\
\hline$<6.0$ & $469(71.3)$ & $95(20.3)$ & $374(79.7)$ & \\
\hline
\end{tabular}

Abbreviations: SSTR somatostatin receptor, NF2 neurofibromatosis type 2, WHO World Health Organization; the asterisk $(*)$ presents statistically significant results
666 meningiomas. We combined qualitative and quantitative data from immunohistochemistry into an immunoreactive score and added clinical prognostic factors to a multivariate analysis. We show that high SSTR2A expression is an independent predictor for unfavorable progression-free survival in meningioma. Possibly a main factor for this result is the observation of a higher rate of SSTR2A expression for grade II meningiomas compared to grade I tumors, which we published recently. Interestingly, the expression rate for grad III tumors is lower, which may express the dedifferentiation of malignant meningiomas [14]. Downregulation of multiple previously strongly expressed genes is frequently observed in recurring meningiomas [16].

Somatostatin receptors are G-protein-coupled transmembrane receptors that regulate numerous functions in different organs [17]. All five SSTRs seem to act by inhibition of 

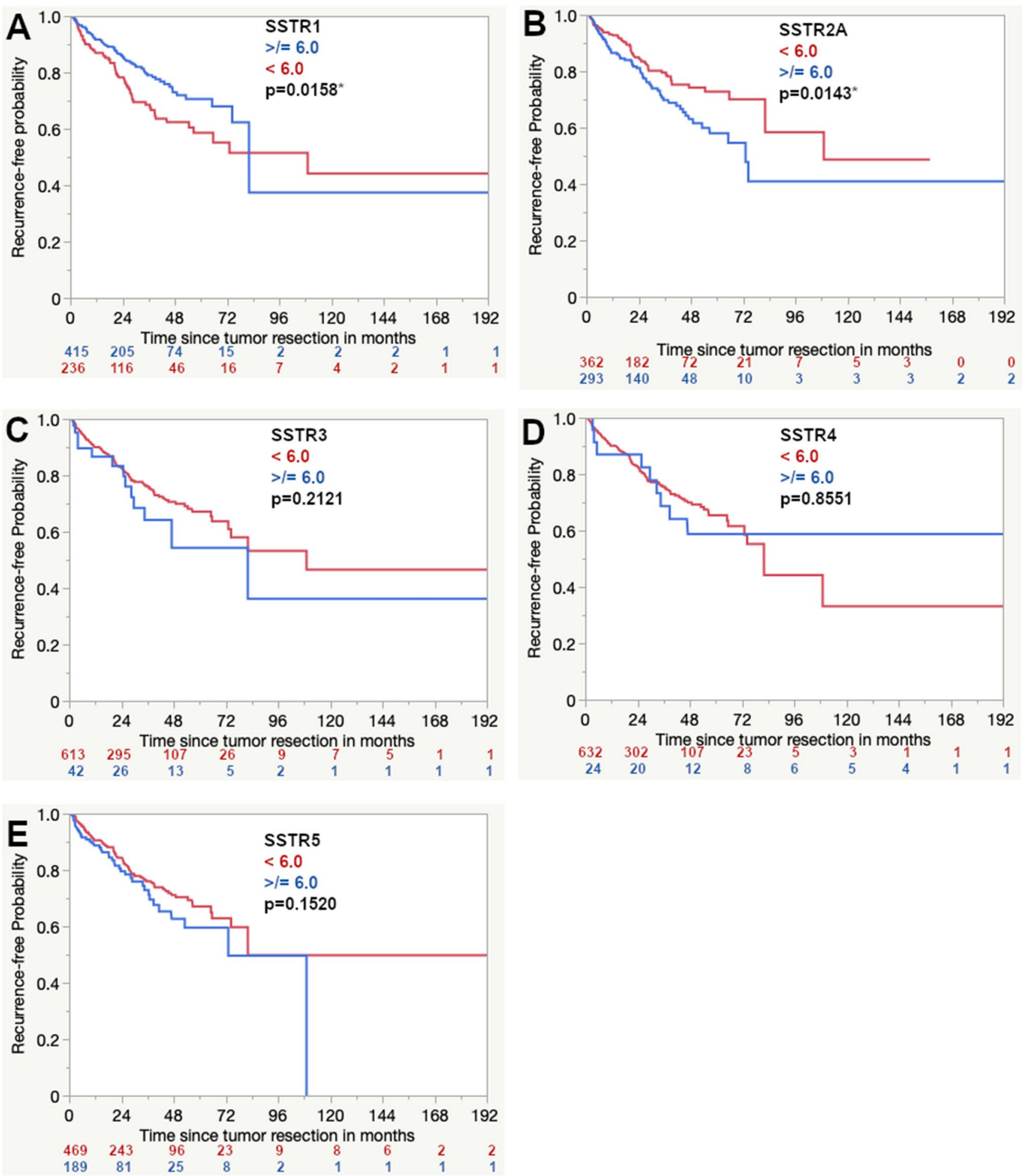

Fig. 1 Univariate analysis of the prognostic impact of the expression of SSTR1 (A), SSTR2A (B), SSTR3 (C), SSTR4 (D), and SSTR5 (E). The asterisks $(*)$ represent statistically significant differences

the adenylate cyclase and subsequent stimulation of phospholipase $\mathrm{C}$ and calcium mobilization [18, 19]. Multiple downstream pathways of somatostatin have been identified resulting in several antiproliferative mechanisms in different tumors, mainly involving the inhibition of cell cycle progression, apoptosis, and angiogenesis [19, 20]. However, high 

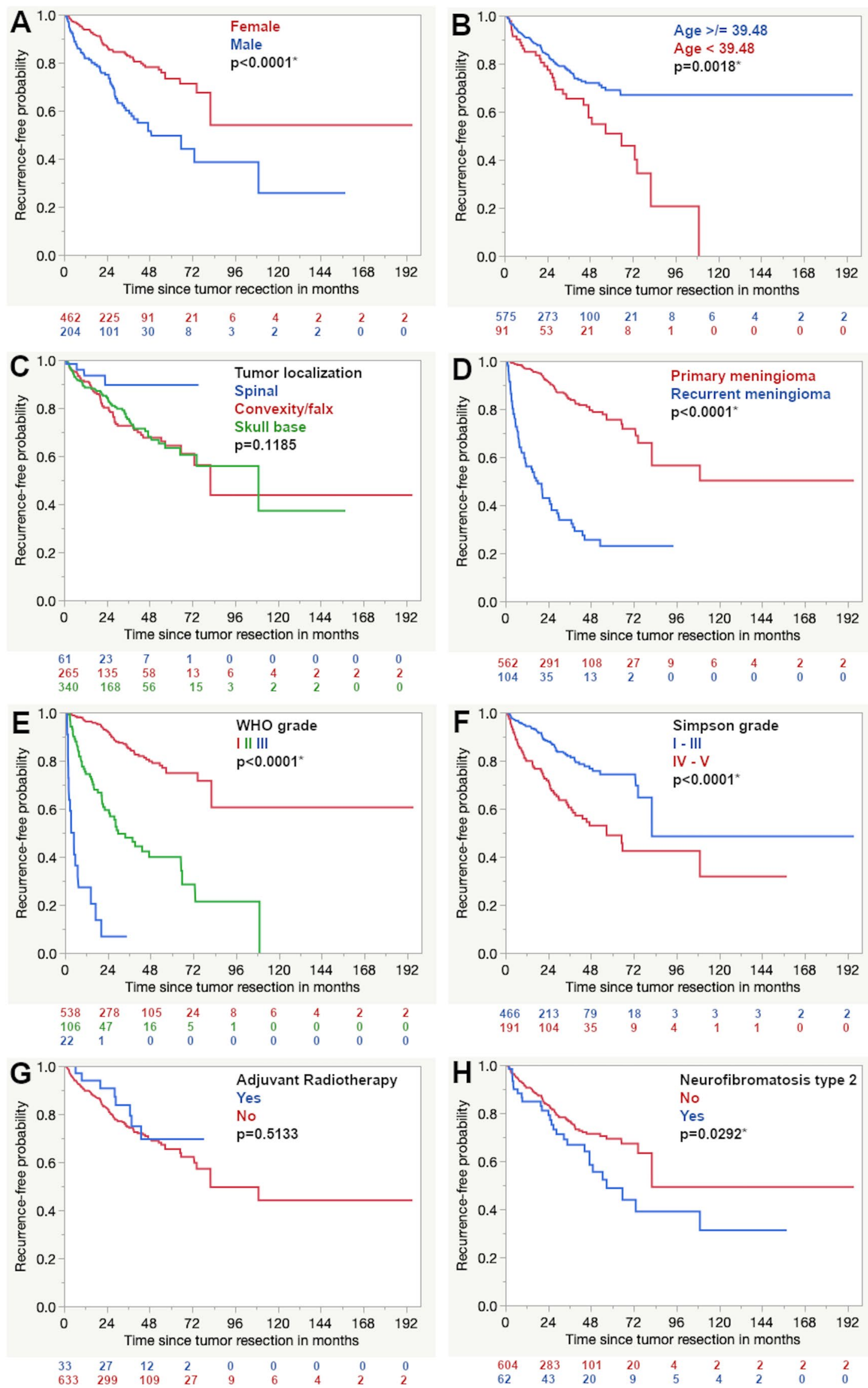
4Fig. 2 Univariate analysis of the prognostic impact of the expression of gender (A), age (B), tumor localization $(\mathbf{C})$, recurrent tumor (D), WHO grade $(\mathbf{E})$, extent of resection according to Simpson $(\mathbf{F})$, adjuvant radiotherapy $(\mathbf{G})$, and neurofibromatosis type $2(\mathbf{H})$. The age cutoff is set according to a CART analysis. The asterisks $\left(^{*}\right)$ represent statistically significant differences

expression levels have been demonstrated in different tumor types, including neuroendocrine tumors, renal cell carcinomas, lymphomas, and meningiomas [19]. If SSTR expression is functionally linked to tumor formation or proliferation, in contrary the known function of SSTRs is unclear. It is important to emphasize that the current knowledge is based on studies in different tumor types and models.

The application of somatostatin showed a dramatic decrease of the incidence of bladder cancer due to the carcinogenic effect of nitrosamine in rats, suggesting a protective effect possibly by supporting apoptosis of dysplastic cells at risk malignification [21]. One possible explanation is that the expression of SSTRs is a last signal response by hormonal proapoptotic influence of cells before further dedifferentiation and tumor formation. Therefore, increased SSTR expression may be a byproduct of increased proliferation and may not necessarily be actively involved in tumor growth.

On the contrary, an older in vitro study revealed that the application of somatostatin and octreotide resulted in increased cell growth of a meningioma cell line, suggesting a stimulatory proliferative effect in meningioma [22]. However, the mechanism of how differences in SSTR expressions may reflect tumor progression remains unclear.

There is some data on the prognostic role of SSTR expression in smaller meningioma series. In 2004, Arena et al. analyzed the expression of SSTR1-5 mRNA in 42 meningiomas and found no correlation with the immunohistochemical expression of MIB-1 and bcl-2, markers for proliferation and apoptosis, respectively. Additionally, a decrease in DNA synthesis was observed when somatostatin was applied to primary cell cultures derived from meningiomas [11]. On the contrary, Barresi et al. evaluated the immunohistochemical expression of SSTR2A in 35 meningiomas. A higher rate of immunopositivity was seen in higher grade meningiomas, and a correlation with increased micro-vessel density and MIB-1 expression was demonstrated [12], suggesting a possible link between more aggressive meningiomas and higher SSTR2A expression. Now our study confirms that a higher expression of SSTR2A is an independent predictor for increased risk meningioma recurrence.

In 2015 , a similar but contrary context was described for SSTR5, in the largest study on SSTR expression in meningiomas so far by Silva and colleagues. Sixty meningiomas were assessed regarding all 5 somatostatin receptors. SSTR5 was more frequently observed in grade I meningiomas. However, a correlation of SSTR5 expression with tumor recurrence or regrowth was not seen [13]. This may have been based on the small number of included cases. However, Silva et al. first described a possible connection of SSTR5 expression and more benign meningioma types. This is in line with the results of our previous study, where we were able to show that the expression of SSTR5 is lower in WHO grade III meningiomas [14]. However, the results of our study do not show a prognostic impact of SSTR5 in the univariate and multivariate analysis.

In summary, previous suggestions of a possible prognostic impact of SSTR expressions in meningioma have now been confirmed in a large retrospective analysis with the inclusion of established prognostic factors in a comprehensive multivariate analysis. Incorporation of SSTR2A into the routine neuropathology staining panel of meningioma may provide additional information regarding tumor progression in meningioma and help in the decision to indicate radiotherapy in otherwise prognostically uncertain cases. However, the mechanism behind the contrary independent prognostic impact of the expression of SSTR2A remains a matter for further research.

The main limitation of this study is its retrospective design and variable follow-up. Longer follow-up periods are desirable. Additionally, including molecular factors that are associated with tumor recurrence/progression would be of interest, such as the TERT promoter mutation [15]. Furthermore, the amount of meningioma tissue for TMA construction and immunohistochemistry may not be adequate in case of heterogenous staining. However, two biopsy cylinders with a diameter of $1 \mathrm{~mm}$ each were extracted and analyzed for each tumor, which is a sufficient amount to minimize heterogeneity in meningioma. We chose to utilize the intensity distribution score that was described by Barresi et al. in 2008 [12] because it incorporates the staining intensity and quantification. Still the scoring system has certain limitations. A score of 6 , for example, can express maximum staining intensity (intensity score of 3 ) in 25-50\% of tumor cells (quantification score 2) or a mediocre staining intensity (score 2) in 50-75\% of tumor cells (quantification score 3 ). Both tumors received an intensity distribution score of 6. It is debatable if tumors with such differences in staining should be graded the same. Further insight into the quantification in comparison with different scoring methods in immunohistochemistry and prognostic data would be of great help to improve the scoring system.

\section{Conclusion}

An increased expression of SSTR2A is an independent negative prognostic factor for meningioma recurrence. 
Table 2 Multivariate analysis including immunohistochemical expression of SSTR1-5 (Cox proportional hazard)

\begin{tabular}{lll}
\hline & Risk ratio (95\%CI) & $p$-value (Prob $>$ Chisq) \\
\hline Male gender & $1.77(1.20-2.63)$ & $0.0042^{*}$ \\
Age $<39.48$ & $1.84(1.03-3.27)$ & $0.0380^{*}$ \\
Recurrent meningioma & $4.74(3.16-7.10)$ & $<0.0001^{*}$ \\
NF2 & $0.64(0.32-1.27)$ & 0.2029 \\
Location & & \\
$\quad$ Convexity/falx vs. & $0.84(0.57-1.25)$ & 0.3943 \\
$\quad$ skull base & $1.27(0.44-3.64)$ & 0.6612 \\
$\quad$ Convexity/falx vs. & $1.50(0.53-4.25)$ & 0.4464 \\
$\quad$ & & \\
$\quad$ Spinal & & \\
Adjull base vs. spinal & & \\
Simpson gradiotherapy $>$ /=4 & $0.25(0.12-0.54)$ & $0.0004^{*}$ \\
WHO classification 2016 & $1.97(1.35-2.88)$ & $0.0005^{*}$ \\
$\quad$ & & \\
I vs. II & $0.29(0.19-0.44)$ & $<0.0001^{*}$ \\
I vs. III & $0.06(0.03-0.11)$ & $<0.0001^{*}$ \\
$\quad$ II vs. III & $0.20(0.11-0.39)$ & $<0.0001^{*}$ \\
SSTR1 $>/=6$ & $0.86(0.59-1.26)$ & 0.4327 \\
SSTR2A $>/=6$ & $1.69(1.16-2.46)$ & $0.0060^{*}$ \\
SSTR3 $>/=6$ & $0.77(0.39-1.52)$ & 0.4497 \\
SSTR4 $>/=6$ & $0.65(0.29-1.47)$ & 0.3029 \\
SSTR5 $>/=6$ & $1.20(0.81-1.80)$ & 0.3687 \\
\hline
\end{tabular}

Abbreviations: SSTR somatostatin receptor, NF2 neurofibromatosis type 2, WHO World Health Organization; the asterisk (*) presents statistically significant results

Supplementary Information The online version contains supplementary material available at https://doi.org/10.1007/s10143-021-01651-w.

\author{
Author contribution Conceptualization: CF, MS, GT, JH, MT, JS, and \\ FB \\ Methodology: CF, JS, and FB \\ Validation: CF, MS, EH, JS, and FB \\ Formal analysis: $\mathrm{CF}$, JS, and FB \\ Investigation: $\mathrm{CF}$, JS, and $\mathrm{FB}$ \\ Resources: GT, JH, MT, JS, and FB \\ Data curation: $\mathrm{CF}, \mathrm{MS}$, JMH, EH, SC, and FB \\ Writing - original draft preparation: CF, JS, and FB \\ FB \\ Writing —review and editing: CF, MS, JMH, EH, JH, MT, JS, and \\ Visualization: $\mathrm{CF}$ and $\mathrm{FB}$ \\ Supervision: FB \\ Project administration: FB \\ All authors have read and agreed to the published version of the \\ manuscript.
}

Funding Open Access funding enabled and organized by Projekt DEAL.

Data availability The dataset is available upon reasonable request.

Code availability Not applicable.

\section{Declarations}

Ethics approval The study was approved by the Clinical Ethics Committee of the University of Tübingen (Project number: 618/2014BO2).

Consent to participate Tumor tissue and clinical data were only used if patient consent was available as defined by the Clinical Ethics Committee of the University of Tübingen.

Consent for publication Not applicable.

Conflict of interest The authors declare no competing interests.

Open Access This article is licensed under a Creative Commons Attribution 4.0 International License, which permits use, sharing, adaptation, distribution and reproduction in any medium or format, as long as you give appropriate credit to the original author(s) and the source, provide a link to the Creative Commons licence, and indicate if changes were made. The images or other third party material in this article are included in the article's Creative Commons licence, unless indicated otherwise in a credit line to the material. If material is not included in the article's Creative Commons licence and your intended use is not permitted by statutory regulation or exceeds the permitted use, you will need to obtain permission directly from the copyright holder. To view a copy of this licence, visit http://creativecommons.org/licenses/by/4.0/.

\section{References}

1. Ostrom QT, Cioffi G, Gittleman H, Patil N, Waite K, Kruchko C, Barnholtz-Sloan JS (2019) CBTRUS Statistical Report: primary brain and other central nervous system tumors diagnosed in the United States in 2012-2016. Neuro Oncol 21:v1-v100. https:// doi.org/10.1093/neuonc/noz150

2. Goldbrunner R, Minniti G, Preusser M, Jenkinson MD, Sallabanda K, Houdart E, von Deimling A, Stavrinou P, Lefranc F, Lund-Johansen M, Moyal EC, Brandsma D, Henriksson R, Soffietti R, Weller M (2016) EANO guidelines for the diagnosis and treatment of meningiomas. Lancet Oncol 17:e383-391. https://doi. org/10.1016/S1470-2045(16)30321-7

3. Lemee JM, Corniola MV, Meling TR (2020) Benefits of re-do surgery for recurrent intracranial meningiomas. Sci Rep 10:303. https://doi.org/10.1038/s41598-019-57254-5

4. Louis DN, Perry A, Reifenberger G, von Deimling A, FigarellaBranger D, Cavenee WK, Ohgaki H, Wiestler OD, Kleihues P, Ellison DW (2016) The 2016 World Health Organization Classification of Tumors of the Central Nervous System: a summary. Acta Neuropathol 131:803-820. https://doi.org/10.1007/ s00401-016-1545-1

5. Sahm F, Schrimpf D, Stichel D, Jones DTW, Hielscher T, Schefzyk S, Okonechnikov K, Koelsche C, Reuss DE, Capper D, Sturm D, Wirsching HG, Berghoff AS, Baumgarten P, Kratz A, Huang K, Wefers AK, Hovestadt V, Sill M, Ellis HP, Kurian KM, Okuducu AF, Jungk C, Drueschler K, Schick M, BewerungeHudler M, Mawrin C, Seiz-Rosenhagen M, Ketter R, Simon M, Westphal M, Lamszus K, Becker A, Koch A, Schittenhelm J, Rushing EJ, Collins VP, Brehmer S, Chavez L, Platten M, Hanggi D, Unterberg A, Paulus W, Wick W, Pfister SM, Mittelbronn M, Preusser M, Herold-Mende C, Weller M, von Deimling A (2017) DNA methylation-based classification and grading system for meningioma: a multicentre, retrospective analysis. Lancet Oncol 18:682-694. https://doi.org/10.1016/S1470-2045(17)30155-9 
6. Suppiah S, Nassiri F, Bi WL, Dunn IF, Hanemann CO, Horbinski CM, Hashizume R, James CD, Mawrin C, Noushmehr H, Perry A, Sahm F, Sloan A, Von Deimling A, Wen PY, Aldape K, Zadeh G, International Consortium on M (2019) Molecular and translational advances in meningiomas. Neuro Oncol 21:i4-i17. https:// doi.org/10.1093/neuonc/noy 178

7. Dash A, Chakraborty S, Pillai MR, Knapp FF Jr (2015) Peptide receptor radionuclide therapy: an overview. Cancer Biother Radiopharm 30:47-71. https://doi.org/10.1089/cbr.2014.1741

8. Reubi JC (2004) Somatostatin and other Peptide receptors as tools for tumor diagnosis and treatment. Neuroendocrinology 80(Suppl 1):51-56. https://doi.org/10.1159/000080742

9. Minutoli F, Amato E, Sindoni A, Cardile D, Conti A, Herberg A, Baldari S (2014) Peptide receptor radionuclide therapy in patients with inoperable meningiomas: our experience and review of the literature. Cancer Biother Radiopharm 29:193-199. https://doi. org/10.1089/cbr.2013.1599

10. Seystahl K, Stoecklein V, Schuller U, Rushing E, Nicolas G, Schafer N, Ilhan H, Pangalu A, Weller M, Tonn JC, Sommerauer M, Albert NL (2016) Somatostatin receptor-targeted radionuclide therapy for progressive meningioma: benefit linked to $68 \mathrm{Ga}-$ DOTATATE/-TOC uptake. Neuro Oncol 18:1538-1547. https:// doi.org/10.1093/neuonc/now060

11. Arena S, Barbieri F, Thellung S, Pirani P, Corsaro A, Villa V, Dadati P, Dorcaratto A, Lapertosa G, Ravetti JL, Spaziante R, Schettini G, Florio T (2004) Expression of somatostatin receptor mRNA in human meningiomas and their implication in in vitro antiproliferative activity. J Neurooncol 66:155-166. https://doi. org/10.1023/b:neon.0000013498.19981.55

12. Barresi V, Alafaci C, Salpietro F, Tuccari G (2008) Sstr2A immunohistochemical expression in human meningiomas: is there a correlation with the histological grade, proliferation or microvessel density? Oncol Rep 20:485-492

13. Silva CB, Ongaratti BR, Trott G, Haag T, Ferreira NP, Leaes CG, Pereira-Lima JF, Oliveira Mda C (2015) Expression of somatostatin receptors (SSTR1-SSTR5) in meningiomas and its clinicopathological significance. Int J Clin Exp Pathol 8:13185-13192

14. Behling F, Fodi C, Skardelly M, Renovanz M, Castaneda S, Tabatabai G, Honegger J, Tatagiba M, Schittenhelm J (2021) Differences in the expression of SSTR1-5 in meningiomas and its therapeutic potential. Neurosurg Rev. https://doi.org/10.1007/ s10143-021-01552-y

15. Sahm F, Schrimpf D, Olar A, Koelsche C, Reuss D, Bissel J, Kratz A, Capper D, Schefzyk S, Hielscher T, Wang Q, Sulman
EP, Adeberg S, Koch A, Okuducu AF, Brehmer S, Schittenhelm J, Becker A, Brokinkel B, Schmidt M, Ull T, Gousias K, Kessler AF, Lamszus K, Debus J, Mawrin C, Kim YJ, Simon M, Ketter R, Paulus W, Aldape KD, Herold-Mende C, von Deimling A (2016) TERT promoter mutations and risk of recurrence in meningioma. J Natl Cancer Inst 108. https://doi.org/10.1093/jnci/djv377

16. Perez-Magan E, Rodriguez de Lope A, Ribalta T, Ruano Y, Campos-Martin Y, Perez-Bautista G, Garcia JF, Garcia-Claver A, Fiano C, Hernandez-Moneo JL, Mollejo M, Melendez B (2010) Differential expression profiling analyses identifies downregulation of $1 \mathrm{p}, 6 \mathrm{q}$, and $14 \mathrm{q}$ genes and overexpression of $6 \mathrm{p}$ histone cluster 1 genes as markers of recurrence in meningiomas. Neuro Oncol 12:1278-1290. https://doi.org/10.1093/neuonc/noq081

17. Lahlou H, Guillermet J, Hortala M, Vernejoul F, Pyronnet S, Bousquet C, Susini C (2004) Molecular signaling of somatostatin receptors. Ann N Y Acad Sci 1014:121-131. https://doi.org/10. 1196/annals.1294.012

18. Patel YC, Greenwood MT, Warszynska A, Panetta R, Srikant CB (1994) All five cloned human somatostatin receptors (hSSTR1-5) are functionally coupled to adenylyl cyclase. Biochem Biophys Res Commun 198:605-612. https://doi.org/10.1006/bbrc.1994. 1088

19. Reubi JC, Laissue JA (1995) Multiple actions of somatostatin in neoplastic disease. Trends Pharmacol Sci 16:110-115. https://doi. org/10.1016/s0165-6147(00)88992-0

20. Susini C, Buscail L (2006) Rationale for the use of somatostatin analogs as antitumor agents. Ann Oncol 17:1733-1742. https:// doi.org/10.1093/annonc/mdl105

21. Szende B, Juhasz E, Lapis K, Schally AV (1992) Inhibition of two-step urinary bladder carcinogenesis by the somatostatin analogue RC-160. Urol Res 20:383-386. https://doi.org/10.1007/ BF00294492

22. Koper JW, Markstein R, Kohler C, Kwekkeboom DJ, Avezaat CJ, Lamberts SW, Reubi JC (1992) Somatostatin inhibits the activity of adenylate cyclase in cultured human meningioma cells and stimulates their growth. J Clin Endocrinol Metab 74:543-547. https://doi.org/10.1210/jcem.74.3.1346787

Publisher's note Springer Nature remains neutral with regard to jurisdictional claims in published maps and institutional affiliations. 